\title{
Effects of lime and sawdust on arsenic reduction in corn planted on the inside of the dyke at Quoc Thai commune, An Phu district, An Giang province
}

\author{
Chinh T. Nguyen ${ }^{*}$, \& Chuong V. Nguyen \\ Faculty of Agriculture and Natural Resources, An Giang University, An Giang, Vietnam
}

ARTICLE INFO
Research Paper
Received: January 17, 2019
Revised: March 25, 2019
Accepted: April 16, 2019
Keywords
Arsenic (As)
Lime
Maize
Quoc Thai commune soil
Sawdust
*Corresponding author
Nguyen Trung Chinh
Email: trungchinhch2khct@gmail.com

\begin{abstract}
Previous research has shown that soil and crops in Quoc Thai commune, An Phu district, An Giang province are severely contaminated with arsenic. The objectives of the experiment were (1) to evaluate effects of lime and sawdust on water $\mathrm{pH}$ and arsenic content in soil and 2) to determine effects of lime and sawdust on arsenic uptake by corn. The experiment was carried out in the field on the inside of the dyke with 4 treatments and 4 replications. The results showed that the treatment of lime combined with sawdust increased water $\mathrm{pH}$ and arsenic content in soil. The arsenic content in stems and leaves $(95.3 \mathrm{mg} / \mathrm{kg})$ and in seeds $(6.33 \mathrm{mg} / \mathrm{kg})$ of the maize was lower than that of the control by $31.9 \%$ and $49.4 \%$, respectively. In brief, the use of lime in combination with sawdust to fertilize plants increased the water $\mathrm{pH}$ and arsenic content in the soil, while reducing the arsenic content in plants.
\end{abstract}

Cited as: Nguyen, C. T., \& Nguyen, C. V. (2019). Effects of lime and sawdust on arsenic reduction in corn planted on the inside of the dyke at Quoc Thai commune, An Phu district, An Giang province. The Journal of Agriculture and Development 18(4), 19-25. 


\title{
Ảnh hưởng của bón vôi và mùn cưa đến sự giảm thiểu asen trên cây bắp trồng trong đê bao tại xã Quốc Thái - An Phú - An Giang
}

\author{
Nguyễn Trung Chính* \& Nguyễn Văn Chương \\ Khoa Nông Nghiệp Và Tài nguyên Thiên Nhiên, Trường Đại Học An Giang, An Giang
}

\section{THÔNG TIN BÀI BÁO}

Bài báo khoa học

Ngày nhận: 17/01/2019

Ngày chỉnh sửa: 25/03/2019

Ngày chấp nhận: 16/04/2019

\section{Từ khóa}

Asen (As)

Cây bắp

Đất trồng ở xã Quốc Thái

Mùn cưa

Vôi

\section{*Tác giả liên hệ}

Nguyễn Trung Chính

Email: trungchinhch2khct@gmail.com

\section{TÓM TẮT}

Nhiều nghiên cứu trước đây cho thấy đất và cây trồng tại xã Quốc Thái - huyện An Phú - tỉnh An Giang bị nhiễm asen (As) nghiêm trọng. Mục tiêu của thí nghiệm là 1) đánh giá ảnh hưởng của bón vôi và mùn cưa đến $\mathrm{pH}$ nước và hàm lượng $\mathrm{As}$ trong đất và 2 ) xác định ảnh hưởng của bón vôi và mùn cưa lên sự hút thu As trên cây bắp. Thí nghiệm được thực hiện tại đồng ruộng trong đê bao với 4 nghiệm thức và 4 lần lặp lại. Kết quả cho thấy, nghiệm thức bón vôi kết hợp mùn cưa làm tăng $\mathrm{pH}$ nước và hàm lượng As trong đất. Hàm lượng As trong thân lá (95,3 $\mathrm{mg} / \mathrm{kg})$ và hạt $(6,33 \mathrm{mg} / \mathrm{kg})$ thấp hơn nghiệm thức đối chứng lần lượt là $31,9 \%$ và 49,4\%. Tóm lại, sử dụng vôi kết hợp mùn cưa để bón cho cây đã làm tăng $\mathrm{pH}$ nước và hàm lượng As trong đất, đồng thời giúp giảm hàm lượng As trong cây trồng.

\section{1. Đặt Vấn Đề}

Ngày nay, khi nguồn nước mặt càng ô nhiễm, nước giếng khoan được coi là nguồn nước đóng vai trò quan trọng cho sự phát triển con người cũng như sự phát triển kinh tế xã hội của mỗi quốc gia. Việc khai thác và sử dụng nước giếng khoan cho các mục đích sinh hoạt, sản xuất, trồng trọt, chăn nuôi,... làm cho tình trạng ô nhiễm nước giếng khoan ngày càng trầm trọng hơn.

Từ năm 2003 dến 2005, chương trình United Nations Children's Fund (UNICEF) đã khảo sát nồng độ asen (As) trong các giếng khoan ở 4 tỉnh đồng bằng sông Cửu Long (ĐBSCL) là An Giang, Đồng Tháp, Long An và Kiên Giang đã cho thấy nguồn nước giếng khoan của các tỉnh vùng đầu nguồn sông Cửu Long như An Giang, Đồng Tháp đều bị nhiễm As rất cao, tỷ lệ các giếng có nồng độ As từ $10 \mu \mathrm{g} / \mathrm{L}$ đến $50 \mu \mathrm{g} / \mathrm{L}$. Ở ĐBSCL, nồng độ As cao trên $10 \mu \mathrm{g} / \mathrm{L}$ chủ yếu tập trung ở vùng ven sông Tiền, sông Hậu và Đồng Tháp Mười. Tại
An Giang, trong số 2.966 mẫu nghiên cứu có 40\% số giếng bị nhiễm trên $50 \mu \mathrm{g} / \mathrm{L}, 16 \%$ nhiễm dưới $50 \mu \mathrm{g} / \mathrm{L}$. Riêng huyện An Phú, tỉnh An giang có $97,3 \%$ số giếng điều tra bị nhiễm As với hàm lượng cao hơn $100 \mu \mathrm{g} / \mathrm{L}$ (253 mẫu trên tổng số 260 mẫu khảo sát) (UNICEF \& IPH, 2006).

Sự hiện diện của As trong nước thủy lợi, trong đất ở mức cao có thể cản trở sự phát triển bình thường của cây trồng với các triệu chứng ngộ độc như "ức chế sự nảy mầm, giảm chiều cao cây, năng suất ngũ cốc thấp hơn" (Tsutsumi, 1980; Frans \& ctv., 1988; Marin \& ctv., 1992), "héo và hoại tử phiến lá" (Frans \& ctv., 1988), "giảm diện tích lá và khả năng quang hợp" (Knauer \& ctv., 1999).

Hiện nay, đất nông nghiệp tại huyện An Phú, An Giang được bao đê khép kín, đã làm hạn chế việc sử dụng nguồn nước sông, người nông dân phải sử dụng nước giếng khoan bị nhiễm As để tưới cho cây trồng. Kết quả làm cho $82,1 \%$ mẫu đất có hàm lượng trung bình As trong đất trồng là $7,89 \mathrm{mg} / \mathrm{kg}$ (Nguyen \& Ngo, 2011). Từ đó, cây 
trồng ở đây bị nhiễm As rất nghiêm trọng. Chính vì vậy, việc tìm ra các biện pháp bón phân giảm thiểu As trên cây bắp trồng tại An Phú, An Giang là cần thiết. Mục tiêu của nghiên cứu này là đánh giá ảnh hưởng của vôi và mùn cưa đến sự hút thu As lên cây bắp.

\section{Vật Liệu và Phương Pháp Nghiên Cứu}

\subsection{Vật liệu nghiên cưu}

Đất trồng bố trí thí nghiệm tại xã Quốc Thái, huyện An Phú, tỉnh An Giang là đất phù sa ngọt trong đê bao, có thành phần cơ giới nhẹ, tơi xốp, thoát nước tốt, thích hợp với nhiều loại cây trồng như ngô, dậu, rau màu.

Giống bắp sử dụng trong thí nghiệm là giống NK4300 Bt/GT biến đổi gen của công ty Syngenta Việt Nam, được biết tới với đặc tính nổi trội là kháng sâu đục thân và thuốc trừ cỏ gốc glyphosate.

\subsection{Phương pháp nghiên cứu}

\subsubsection{Bố trí thí nghiệm}

Nghiên cứu được bố trí thí nghiệm cho cây bắp theo khối hoàn toàn ngẫu nhiên. Thí nghiệm được bố trí gồm 4 nghiệm thức với 4 lần lặp lại: Nghiệm thức 1 (NT1) là đối chứng (Không bón vôi và mùn cưa); Nghiệm thức 2 (NT2): bón vôi (Liều lượng 02 tấn $\mathrm{CaO} / \mathrm{ha}$ ); Nghiệm thức 3 (NT3): bón mùn cưa (Liều lượng 02 tấn/ha); Nghiệm thức 4 (NT4): bón vôi kết hợp mùn cưa (Liều lượng 02 tấn/ha theo tỉ lệ 1:1). Chia làm 03 giai đoạn bón: Làm đất (50\% lượng vôi; mùn cưa; vôi kêt hợp mùn cưa); 15 ngày sau gieo (25\% lượng vôi; mùn cưa; vôi kết hợp mùn cưa) và 30 ngày sau gieo (25\% lượng vôi; mùn cưa; vôi kết hợp mùn cưa).

Diện tích mỗi lần lặp lại của mỗi nghiệm thức là $18 \mathrm{~m}^{2}(4 \mathrm{~m} \times 4,5 \mathrm{~m})$. Trồng theo hàng đơn với khoảng cách cây với nhau là $20 \mathrm{~cm}$ (gieo 01 cây/hốc), hàng cách nhau $1 \mathrm{~m}$.

Chế độ nước tưới: Tưới nước giếng khoan có hàm lượng As trung bình là $557 \mu \mathrm{g} / \mathrm{L}$ (Do, 2017). Tưới đủ ẩm cho cây (từ 1 - 10 ngày sau gieo tưới 1 lần/ngày; giai đoạn sau đó tưới 2 - 3 lần/ngày).

Phân bón: Công thức phân bón (NPK kg/ha) 250 - 90 - 60, chia thành 04 đợt bón như sau: Bón lót: Toàn bộ lượng phân lân; bón thúc 1: Cây bắp đạt 3 - 4 lá, bón $40 \%$ đạm và $50 \%$ kali; bón thúc
2: Cây bắp đạt 9 - 10 lá, bón $30 \%$ đạm và $50 \%$ kali; bón thúc 3: Cây bắp trước khi trổ cờ $5-7$ ngày, bón $30 \%$ đạm còn lại.

\subsubsection{Phân tích mẫu}

Đất: Kiểm tra $\mathrm{pH}$ nước và As trong đất trước thí nghiệm và sau thí nghiệm. Thu mẫu đất: Mẫu đất được thu ở độ sâu $0-20 \mathrm{~cm}$. Trong mỗi mẫu thu 05 điểm theo đường chéo góc, sau đó trộn chung lấy mẫu đại diện. Mẫu sau khi thu được chứa trong các túi nhựa được kí hiệu và vận chuyển về phòng thí nghiệm. Mẫu được phơi ở nhiệt độ phòng đến khi khô, sau đó được nghiền và qua rây có mắt lưới $0,5 \mathrm{~mm}$. Tiến hành đo $\mathrm{pH}$ nước (đất/nước tỉ lệ 1:2,5) và phân tích As trong đất.

Phân tích hàm lượng As tổng số (tính theo hàm lượng chất khô - đơn vị tính là $\mathrm{mg} / \mathrm{kg}$ ) trong thân lá và hạt: Sau khi thu hoạch, thu mẫu thân lá và hạt, chứa trong các túi nhựa được ký hiệu và vận chuyển về phòng thí nghiệm. Mẫu được phơi ở nhiệt độ phòng đến khi khô, sau đó được nghiền và qua rây có mắt lưới $0,5 \mathrm{~mm}$. Tiến hành phân tích As.

Qui trình phân tích As trong đất, thân lá và hạt (Nguyen, 2014):

Cân $1 \mathrm{~g}$ mẫu khô chuyển vào bình vô cơ. Thêm $10 \mathrm{~mL} \mathrm{HNO}_{3}$ tỉ lệ $1: 1$, lắc kỹ và đậy lại bằng vật liệu có thể hoàn lưu hơi. Đun nóng đến $95^{\circ} \mathrm{C}$ và để $10-15$ phút không cần để sôi. Làm nguội mẫu, thêm $5 \mathrm{~mL} \mathrm{HNO}_{3}$ đậm đặc, đậy lại và reflux 30 phút. Nếu có khói màu nâu bốc ra, lặp lại sự oxy hóa bởi việc thêm $5 \mathrm{~mL} \mathrm{HNO}_{3}$ đậm đặc cho đến khi không còn khói màu nâu là mẫu đã hoàn thành phản ứng với $\mathrm{HNO}_{3}$. Dùng loại thủy tinh trong suốt hoặc hệ thống hoàn lưu hơi, cho dung dịch bay hơi chính xác $5 \mathrm{~mL}$ nhưng không được sôi hoặc là đun nóng đến $95^{\circ} \mathrm{C}$ không sôi trong 2 giờ. Luôn giữ cho sự che đậy dung dịch ở đáy bình.

Sau bước trên hoàn thành và làm nguội mẫu, thêm $2 \mathrm{~mL}$ nước và $3 \mathrm{~mL} \mathrm{H} \mathrm{H}_{2} \mathrm{O}_{2} 30 \%$. Cẩn thận không làm mất mẫu khi sự sủi bọt mãnh liệt quá mức. Đun nóng đến khi sự sủi bọt dịu xuống và làm nguội bình. Tiếp tục cho thêm $\mathrm{H}_{2} \mathrm{O}_{2} 30 \%$ với việc làm ấm cho đến khi sự sủi bọt thấp nhất hoặc thấy mẫu không biến đổi nữa. (Chú ý: Không được cho quá $10 \mathrm{~mL} \mathrm{H}_{2} \mathrm{O}_{2} 30 \%$ ).

Đậy mẫu và tiếp tục đun cho đến khi thể tích mẫu giảm đến chính xác $5 \mathrm{~mL}$ hoặc đun ở $95^{\circ} \mathrm{C}$ nhưng không để sôi trong 2 giờ. Luôn luôn đậy 
bình vô cơ trong lúc đun.

Sau khi làm nguội, hòa loãng lên $100 \mathrm{~mL}$ bằng nước. Ly tâm hoặc để lắng cặn và lọc mẫu để loại bỏ chất cặn. Mẫu này được đem phân tích bởi phương pháp GF-AAS.

Thang đánh giá tham khảo hàm lượng As trong đất và nông sản: Theo QCVN 03:2008/BTNMT của MONRE (2008) về giới hạn hàm lượng As trong đất nông nghiệp là $12,0 \mathrm{mg} / \mathrm{kg}$ đất khô. Theo QCVN 01-12:2009/ BNNPTNT của MARD (2009) về giới hạn hàm lượng As tối đa trong nông sản là $2,0 \mathrm{mg} / \mathrm{kg}$ chất khô.

\subsubsection{Phân tích thống kê}

Số liệu được xử lý bằng phần mềm Microsoft Excel và sử dụng phần mềm Statgraphics Centurion XV để thống kê sự khác biệt giữa các nghiệm thức.

\subsection{Thời gian và địa điểm nghiên cứu}

Thí nghiệm được thực hiện trong vụ Đông Xuân năm 2017 tại xã Quốc Thái, huyện An Phú, tỉnh An Giang.

\section{Kết Quả và Thảo Luận}

\section{1. Ảnh hưởng của bón vôi và mùn cưa đến $\mathrm{pH}$ và hàm lượng As trong đất}

\subsection{1. Ảnh hưởng của chế độ bón vôi và mùn cưa đến pH nước trung bình trong đất}

Kết quả phân tích ở Bảng 1 thể hiện đất trước thí nghiệm không có sự khác biệt về $\mathrm{pH}$ nước trung bình trong đất giữa 4 nghiệm thức, dao động từ 7,28 - 7,33. Sau thí nghiệm, độ pH nước trung bình trong đất có khác biệt ý nghĩa thống kê ở mức $5 \%$, dao động từ $7,10-7,45$. Nghiệm thức bón vôi kết hợp mùn cưa có độ $\mathrm{pH}$ nước trung bình trong đất cao nhất $(7,45)$, kế đến là nghiệm thức bón vôi $(7,40)$, nghiệm thức bón mùn cưa $(7,32)$, nghiệm thức đối chứng là có độ pH nước trung bình trong đất thấp nhất $(7,10)$. Nghiệm thức đối chứng có pH nước trung bình trong đất giảm (từ 7,30 xuống 7,10 ). Các nghiệm thức bón vôi, bón mùn cưa, bón vôi kết hợp mùn cưa có độ $\mathrm{pH}$ nước trung bình trong đất sau thí nghiệm đều tăng, tăng nhiều nhất là ở nghiệm thức bón vôi kết hợp mùn cưa (từ 7,33 lên 7,45 ). Kết quả này cũng phù hợp với nghiên cứu của Tat \& ctv. (2016) rằng, pH tăng ở các nghiệm thức bón vôi và phân hữu cơ, khác biệt ý nghĩa thống kê so với nghiệm thức đối chứng (không bón vôi và phân hữu cơ). Theo Vo \& ctv. (2008), phân hữu cơ góp phần giúp tăng pH đất. Bên cạnh đó, vôi cung cấp thêm $\mathrm{Ca}^{2+}$ cao giúp tăng $\mathrm{pH}$ đất, đồng thời $\mathrm{Ca}^{2+}$ thay thế $\mathrm{Na}^{+}$trao đổi trên phức hệ hấp thu, đưa $\mathrm{Na}^{+}$đưa ra ngoài dung dịch đất, dễ dàng rửa trôi khỏi môi trường đất (Makoi \& Verplancke, 2010). Qua đó cho thấy việc bón vôi và mùn cưa đã ảnh hưởng đến sự thay đổi $\mathrm{pH}$ nước trong đất.

\subsection{2. Ảnh hưởng của chế độ bón vôi và mùn cưa đến hàm lượng As trong đất}

Kết quả phân tích trình bày trong Bảng 2 cho thấy khác biệt ý nghĩa thống kê $5 \%$ giữa các nghiệm thức về hàm lượng As trung bình trong đất trước thí nghiệm, trong đó hàm lượng As trung bình trong đất cao nhất là $33,6 \mathrm{mg} / \mathrm{kg}$ và thấp nhất là $31,6 \mathrm{mg} / \mathrm{kg}$. Qua đó thấy được nguồn đất trồng tại xã Quốc Thái, huyện An Phú bị nhiễm As nghiêm trọng. Bên cạnh đó, hàm lượng As trung bình trong đất sau thí nghiệm có sự khác biệt ý nghĩa thống kê $5 \%$, đạt giá trị cao nhất là 46,6 mg/kg (tăng 13,0 mg/kg so với đất trước thí nghiệm) ở nghiệm thức bón vôi kết hợp mùn cưa và thấp nhất là nghiệm thức đối chứng đạt $34,7 \mathrm{mg} / \mathrm{kg}$ (tăng $3,1 \mathrm{mg} / \mathrm{kg}$ so với đất trước thí nghiệm), nghiệm thức bón vôi đạt $44,5 \mathrm{mg} / \mathrm{kg}$ (tăng $11,0 \mathrm{mg} / \mathrm{kg}$ so với đất trước thí nghiệm), nghiệm thức bón mùn cưa đạt $37,1 \mathrm{mg} / \mathrm{kg}$ (tăng $4,2 \mathrm{mg} / \mathrm{kg}$ so với đất trước thí nghiệm). Kết quả này phù hợp với nghiên cứu của Huq \& ctv. (2011) rằng, hàm lượng As được ghi nhận cao hơn trong đất có bón phân cân đối so với đất không được bón phân. Qua đây cho thấy đất trồng ở đây bị nhiễm As rất nghiêm trọng do sử dụng nước giếng khoan bị nhiễm As để canh tác, vượt quá QCVN 03:2008/BTNMT (12 mg/kg). Từ đó, việc bón vôi kết hợp mùn cưa có hiệu quả hơn trong việc cố định As trong đất trồng.

\section{2. Ảnh hưởng của bón vôi và mùn cưa lên sự hấp thu As trên cây bắp tại xã Quốc Thái, huyện An Phú, tỉnh An Giang}

Bảng 3 cho thấy các nghiệm thức của thân lá và hạt có khác biệt ý nghĩa thống kê $5 \%$ trong thí nghiệm. Hàm lượng As trung bình trong thân lá cao hơn trong hạt ở tất cả các nghiệm thức, hàm lượng As trung bình trong thân lá đạt 95,3 - $140 \mathrm{mg} / \mathrm{kg}$, còn trong hạt trung bình đạt 6,33 
Bảng 1. Ảnh hưởng của bón vôi và mùn cưa đến $\mathrm{pH}$ nước trong đất (Tháng 11/2017)

\begin{tabular}{lcc}
\hline \multirow{2}{*}{ Nghiệm thức } & \multicolumn{2}{c}{ Độ pH nước trung bình trong đất } \\
\cline { 2 - 3 } & Trước thí nghiệm & Sau thí nghiệm \\
\hline Đối chứng & 7,30 & $7,10^{\mathrm{d}}$ \\
Bón vôi & 7,31 & $7,40^{\mathrm{b}}$ \\
Bón mùn cưa & 7,28 & $7,32^{\mathrm{c}}$ \\
Bón vôi kết hợp mùn cưa & 7,33 & $7,45^{\mathrm{a}}$ \\
\hline F & ns & $*$ \\
CV\% & 0,28 & 2,11 \\
\hline a-dón
\end{tabular}

thống kê ở mức $5 \%(*)$; ns: không khác biệt ý nghĩa thống kê.

Bảng 2. Hàm lượng As trung bình trong đất trước và sau thí nghiệm (Tháng $11 / 2017)$

\begin{tabular}{lcc}
\hline \multirow{2}{*}{ Nghiệm thức } & \multicolumn{2}{c}{ Hàm lượng As trung bình trong đất $(\mathrm{mg} / \mathrm{kg})$} \\
\cline { 2 - 3 } & Trước thí nghiệm & Sau thí nghiệm \\
\hline Đối chứng & $31,6^{\mathrm{c}}$ & $34,7^{\mathrm{d}}$ \\
Bón vôi & $33,5^{\mathrm{a}}$ & $44,5^{\mathrm{b}}$ \\
Bón mùn cưa & $32,9^{\mathrm{b}}$ & $37,1^{\mathrm{c}}$ \\
Bón vôi kết hợp mùn cưa & $33,6^{\mathrm{a}}$ & $46,6^{\mathrm{a}}$ \\
\hline F & $*$ & $*$ \\
CV\% & 2,78 & 14,0 \\
\hline a-d Trong cùng một cột, những số có chữ theo sau khác nhau thì có khác biệt ý nghĩa thống kề \\
ở mức 5\% (*).
\end{tabular}

Bảng 3. Ảnh hưởng của chế độ bón vôi và mùn cưa lên hàm lượng As trung bình trong các bộ phận của cây (Tháng 11/2017)

\begin{tabular}{lcc}
\hline \multirow{2}{*}{ Nghiệm thức } & \multicolumn{1}{c}{ Hàm lượng As trong các bộ phận $(\mathrm{mg} / \mathrm{kg})$} \\
\cline { 2 - 3 } & Thân lá & Hạt \\
\hline Đối chứng & $140^{\mathrm{a}}$ & $12,5^{\mathrm{a}}$ \\
Bón vôi & $107^{\mathrm{c}}$ & $8,4^{\mathrm{c}}$ \\
Bón mùn cưa & $114^{\mathrm{b}}$ & $11,0^{\mathrm{b}}$ \\
Bón vôi kết hợp mùn cưa & $95,3^{\mathrm{d}}$ & $6,33^{\mathrm{d}}$ \\
\hline F & $*$ & $*$ \\
CV\% & 16,6 & 28,7 \\
\hline
\end{tabular}

a-d Trong cùng một cột, những số có chữ theo sau khác nhau thì có khác biệt ý nghĩa thống kê ở mức $5 \%(*)$.

- $12,5 \mathrm{mg} / \mathrm{kg}$, đều vượt ngưỡng cho phép là 2,0 $\mathrm{mg} / \mathrm{kg}$ của QCVN 01-12:2009/ BNNPTNT. Nếu sử dụng hạt làm thực phẩm lâu dài thì As sẽ tích tụ ngày càng nhiều, gây hại cho cơ thể (Scragg, 2006). Để khắc phục hạn chế này, cần có những nghiên cứu tiếp tục để tìm ra loại phân bón, cách bón và hàm lượng phân bón cho phù hợp; hoặc có những biện pháp chế biến bắp cho phù hợp như: rửa kỹ bắp trước khi nấu, rồi hấp chín bằng hơi nước, cách làm này giống như cách loại bỏ As trong gạo đã được nghiên cứu bởi Sengupta \& ctv. (2006). Ngoài ra, theo Nam (2018) có những phương pháp để thải As ra khỏi cơ thể bằng chế dộ ăn uống và bổ sung các thực phẩm như: ăn rau quả giàu Vitamin $\mathrm{C}$, rau lá xanh đậm, thảo mộc (ngò, húng, quế, gừng, hương thảo, hành, tỏi), quả óc chó, quả chia, tảo Chlorella, nước xương, nước lọc. 
Hàm lượng As trung bình trong hạt có sự khác biệt rõ rệt, đặc biệt là ở nghiệm thức đối chứng với hàm lượng As trong hạt trung bình là 12,5 $\mathrm{mg} / \mathrm{kg}$ và thấp nhất là nghiệm thức bón vôi kết hợp mùn cưa trung bình đạt $6,33 \mathrm{mg} / \mathrm{kg}$, nhỏ hơn gần 2 lần so với nghiệm thức đối chứng. Nếu chỉ bón vôi hoặc mùn cưa thì hiệu quả thấp hơn so với bón kết hợp vôi và mùn cưa với hàm lượng As trong hạt trung bình đạt $8,4 \mathrm{mg} / \mathrm{kg}$ và 11,0 $\mathrm{mg} / \mathrm{kg}$.

Đối với hàm lượng As trung bình trong thân lá thì các nghiệm thức cũng có sự khác biệt với nhau, cụ thể là ở nghiệm thức bón vôi kết hợp mùn cưa, hàm lượng As có giá trị trung bình thấp nhất đạt $95,3 \mathrm{mg} / \mathrm{kg}$ và cao nhất ở nghiệm thức đối chứng đạt $140 \mathrm{mg} / \mathrm{kg}$. Hàm lượng As trung bình trong thân lá ở nghiệm thức bón vôi là 107 $\mathrm{mg} / \mathrm{kg}$, còn ở nghiệm thức bón mùn cưa là 114 $\mathrm{mg} / \mathrm{kg}$. Nhìn chung, hàm lượng As trung bình trong thân lá ở cả 4 nghiệm thức là rất cao.

Các nghiệm thức có bón phân (vôi và mùn cưa) đã giúp làm giảm sự hấp thu và tích lũy As trong thân lá và hạt của cây bắp. Trong đó hiệu quả nhất là nghiệm thức bón vôi kết hợp với mùn cưa, bởi vì vôi cố định As lại trong đất và mùn cưa giữ As lại trên mặt đất. Chính vì vậy, hàm lượng As trong đất ở nghiệm thức bón vôi kết hợp với mùn cưa là cao nhất, còn hàm lượng As trong cây ở nghiệm thức này là thấp nhất. Kết quả này phù hợp với nghiên cứu của Tan \& ctv. (2011) rằng, bón vôi cho đất trồng nhiễm As làm giảm sự hấp thu kim loại này vào cây trồng trung bình từ $40 \%$ - $50 \%$ và tối đa là $70 \%$. Sự giảm thiểu hấp thu As là do sự bất động của chúng trong đất. Bên cạnh đó, theo kết quả nghiên cứu của Nguyen (2014) sử dụng vôi và mùn cưa làm giảm sự tích lũy kim loại nặng trên rau xà lách và rau cải xanh cho thấy tác động khá rõ đến sinh trưởng của cây và làm giảm đáng kể sự tích lũy kim loại nặng trong rau cải xanh cũng như rau xà lách. So với mùn cưa, bón vôi có tác động làm giảm tích lũy kim loại nặng trong rau màu thể hiện rõ rệt hơn. Theo Huq \& ctv. (2008) báo cáo rằng, ứng dụng chất hữu cơ đã có thể giảm tích lũy As khoảng $75 \%$ trong các bộ phận trên cây trồng. Tương tự như vậy, sự ứng dụng kết hợp các loại phân hữu cơ có thể giảm hàm lượng As là $33,47 \%$ và $36,87 \%$ trong ngũ cốc nguyên hạt và xay hạt tương ứng so với đất đối chứng không sử dụng phân hữu cơ.

Vì vậy, khi trồng bắp ở đất nhiễm As như xã Quốc Thái, An Phú nên bón vôi kết hợp mùn cưa để giảm sự hút thu As vào cây trồng.

\section{Kết Luận và Kiến Nghị}

\subsection{Kết luận}

Độ $\mathrm{pH}$ nước và hàm lượng As trong đất tăng khi bón vôi và mùn cưa vào đất, tăng nhiều nhất là nghiệm thức có bón vôi kết hợp mùn cưa.

Việc bón vôi và mùn cưa làm cho hàm lượng As trong thân lá và hạt của cây bắp giảm hơn so với trồng không bón vôi và mùn cưa.

Đối với nghiệm thức bón vôi kết hợp với mùn cưa (02 tấn/ha) cho thấy hiệu quả tốt nhất, mức độ giảm sự hút thu As từ môi trường đất vào trong thân lá và hạt là thấp nhất, kế đến là nghiệm thức bón vôi, bón mùn cưa vẫn cho kết quả có hàm lượng As trong thân lá và hạt thấp hơn đối chứng lần lượt là $18,6 \%$ đến $31,9 \%$ và $12,0 \%$ đến $49,4 \%$.

Như vậy, khi cây trồng có bón thêm vôi kêt hợp mùn cưa (02 tấn/ha) đã làm tăng $\mathrm{pH}$ nước và hàm lượng As trong đất, đồng thời giúp giảm hàm lượng As trong cây trồng.

\subsection{Kiến nghị}

Điều chỉnh phù hợp lượng vôi kết hợp mùn cưa bón cho cây trồng ở điều kiện đồng ruộng, đặc biệt đối với cây bắp để giảm hút thu As và đạt dưới ngưỡng cho phép.

Cần có những biện pháp lâu dài để góp phần làm giảm hấp thu hàm lượng As vào cây trồng như cải tạo hệ thống thủy lợi để có thể cung cấp nước sông tưới cho cây trồng đồng thời sử dụng phân bón đạt chất lượng để làm giảm hàm lượng tích lũy As trong đất và trong cây trồng.

\section{Tài Liệu Tham Khảo (References)}

Do, L. T. V. (2017). Analytical results. Can Tho University, Can Tho, Vietnam.

Frans, R., Horton, D., \& Burdette, L. (1988). Influence of MSMA on straighthead, arsenic uptake and growth response in rice (Oryza sativa). Report Series-Arkansas Agricultural Experiment Station 30, 1-12.

Huq, S. M. I., \& Joardar, J. C. (2008). Effect of balanced fertilization on arsenic and other heavy metals uptake in rice and other crops. Bangladesh Journal of Agriculture and Environment 4, 177-191.

Huq, S. M. I., Sultana, S., Chakraborty, G., \& Chowdhury, M. T. A. (2011). A mitigation approach to alleviate arsenic accumulation in rice through balanced fertilization. Applied and Environmental Soil Science 2011, 1-8. 
Knauer, K., Behra, R., \& Hemond, H. (1999). Toxicity of inorganic and methylated arsenic to algal communities from lakes along an arsenic contamination gradient. Aquatic Toxicology 46(3-4), 221-230.

Makoi, J. H., \& Verplancke, H. (2010). Effect of Gypsum placement on the physical chemical properties of a saline sandy loam soil. Australian Journal of Crop Science 4(7), 556-563.

MARD (Ministry of Agriculture and Rural Development). (2009). Livestock feeds - Maximum allowable levels of antibiotics, phamarceutics, microorganisms, and heavy metals in complete feeds for pigs. Ha Noi, Vietnam: MARD Office.

Marin, A. R., Masscheleyn, P. H., \& Patrick, W. H. (1992). The influence of chemical form and concentration of arsenic on rice growth and tissue arsenic concentration. Plant and Soil 139(2), 175-183.

MONRE (Ministry of Natural Resources and Environment). (2008). National technical regulations on permissible heavy metals in soil. Ha Noi, Vietnam: MONRE Office.

Nam, P. (2018). Detoxicity of heavy metals. Retrieved March 23, 2018, from https://coachnamphuong.com/posts/thai-dockim-loai-nang/.

Nguyen, C. V., \& Ngo, H. N. (2011). Evaluation of asernic and cadimi accumulation in soil and corn in An Phu district, An Giang province. Can Tho University Journal of Science 38, 106-109.

Nguyen, T. T. T. (2014). Evaluation of $\mathrm{Cu}, \mathrm{Pb}$ and $Z n$ absorption and use of fertilizer to reduce their accumulation in broccoli and lettuce. (Unpublished master's thesis). Can Tho University, Can Tho, Vietnam.
Scragg, A. (2006). Environmental Biotechnology $\left(22^{\text {nd }}\right.$ ed.). Oxford, UK: Oxford University Press.

Sengupta, M. K., Hossain, M. A., Mukherjee, A., Ahamed, S., Das, B., Nayak, B., Pal, A., \& Chakraborti, D. (2006). Arsenic burden of cooked rice: Traditional and modern methods. Food and chemical toxicology 44(11), 1823-1829.

Tan, W. N., Li, Z. A., Qiu, J., Zou, B., Li, N. Y., Zhuang, P., \& Wang, G. (2011). Lime and phosphate could reduce cadmium uptake by five vegetables commonly grown in South China. Pedosphere 21(2), 223-229.

Tat, T. A., Le, D. V., Vo, G. T., Nguyen, T. T. B., Trang, C. N. L., \& Dao, D. L. K. (2016). Effects of compost amendment and lime on the improvement of rice yield and adverse properties of saline soil in greenhouse conditions. Can Tho University Journal of Science Agriculture 4, 84-93.

Tsutsumi, M. (1980). Intensification of arsenic toxicity to paddy rice by hydrogen sulfide and ferrous iron. I. Induction of bronzing and iron accumulation in rice by arsenic. Soil Science and Plant Nutrition 26(4), 561569.

UNICEF \& IPH (UNICEF \& Institute Public Health Ho Chi Minh City). (2006). Arsenic issue in Mekong, Red river deltas and arsenic mitigation. Ho Chi Minh City, Vietnam: Unicef \& IPH office.

Vo, G. T., Duong, V. M., Nguyen, H. M., Nguyen, D. M., Nguyen, P. T. M., Tran, L. B., Pham, T. N. M., \& Phan, B. T, (2008). A final report on production of composting organic fertilizer. Can Tho University, Can Tho, Vietnam. 